\title{
Perceiving Music Through the Lens of Synaesthesia and Absolute Pitch
}

Solange Glasser

First Published July 31, 2021 Research Article

https://doi.org/10.1177/03010066211034439

\section{Abstract}

Synaesthesia and absolute pitch (AP) are two rare conditions that occur more frequently within populations of artistic professionals. Current thinking surrounding synaesthesia and $\mathrm{AP}$ and their relationship to music perception form the focus of this article. Given that synaesthesia has rarely been discussed in the music literature, the article surveys and consolidates general neurobiological, psychological, and behavioural evidence to summarise what is currently known on this topic, in order to link this back to the conditions that most relate to music. In contrast, research on AP is now well established in the music literature, but the important gap of linking AP to other conditions such as synaesthesia has yet to be fully explored. This article investigates the potential relationship between synaesthesia and AP for musicians who possess both conditions by systematically comparing the definitions, classifications, prevalence, diagnoses, and impacts on music perception of synaesthesia and AP and provides insights into the varying states of the literature and knowledge of both conditions. In so doing, this article aims to facilitate a greater understanding of music and auditory forms of synaesthesia and their interaction with AP and encourage increased research effort on this important topic.

\section{Keywords}

synaesthesia, synesthesia, absolute pitch, perfect pitch, perception, auditory perception, pitch processing, musical ability, musical development, cognition

What might it be like to hear a musical stimulus and automatically link it with a particular taste, or read musical notation and involuntarily internalise the score through images or colours? Alternatively, what might it be like to hear a tone and know exactly what pitch was being played without any external reference being involved? As will be shown in this article, two abilities related to the above phenomena — synaesthesia and absolute (or perfect) pitch — are relatively rare conditions among the normal population, but comparably much more common within a population of music professionals.

In order to explore the above questions, this article examines current thinking surrounding synaesthesia and absolute pitch (AP). Given that synaesthesia has rarely been discussed in the music literature, it considers general psychological research in order to link this back 
to the conditions that most relate to music. In contrast, the literature on AP is now well established, but the important gap of linking AP to other conditions such as synaesthesia has, to date, not been adequately explored. Consequently, research on the relationship between these two conditions forms an important part of the following discussion.

To investigate the potential interaction between synaesthesia and AP for musicians who possess both conditions, it is necessary to start by identifying what synaesthesia and AP have in common, or what differentiates these two conditions from each other. Table 1, which is based on a detailed summary by Glasser (in press), provides a starting point by comparing how synaesthesia and AP are defined, classified, occur within the community, can be diagnosed, and how they may impact on music perception.

Table 1. A comparative table of the definitions, classifications, prevalence, diagnoses, and impacts on music perception of synaesthesia and absolute pitch (based on Glasser, 2018, in press).

\section{Synaesthesia}

Definition A perceptual phenomenon in which the stimulation of one sensory or cognitive pathway leads to involuntary experiences in a second sensory or cognitive pathway.

Classification Classified as developmental, acquired, or artificial. Developmental synaesthesia can be further classified as either perceptual or cognitive, and unimodal, bimodal, or multimodal (see Figure 1).

Prevalence $\approx 4.4 \%$ of the general population.

Diagnosis/Test

Synaesthesia, $A P$, and music perception

General studies of synaesthesia,
Generally done by means of consistency tests and/or selfreport. creativity, and artistic ability exist, with a paucity of published studies to date that have specifically looked at the influence of synaesthesia on music perception.

\section{Absolute Pitch}

The ability to label or produce a note of a given pitch in the absence of a reference note, with AP possessors providing pitch labels rapidly and effortlessly.

Classified according to the extent of the AP ability: subgroups include AP1-4 and Groups A-C. To date, consensus on a standardised classification system has not been reached.

Relatively unknown in the general population. Estimates vary between $4 \%-65 \%$ of music sub-populations. Pitch-labelling of piano and/or pure tones; no consensus on criteria.

The performance of AP possessors on tasks related to high-level pitch processing differs from the performance of non-possessors, with enhancements for AP possessors in pitch memory, musical dictation, and interval identification, while relative pitch processing is negatively impacted. 


\section{Definition}

\section{Synaesthesia}

The word synaesthesia (also spelt "synesthesia") is derived from the Greek words syn (union or join) and aesthesis (sensation or perception): literally meaning joint perception, or a union of the senses (Cytowic, 1989, 2002). The term synaesthesia, however, signifies different notions, realities, particularities, and perspectives to different people in different contexts, which in the research literature are described according to three possible forms of synaesthesia (see Figure 1). The first two forms of synaesthesia are classified as authentic, whereby the synaesthetic percepts experienced by the synaesthete are involuntary (Cytowic, 1989, 2002). In contrast, artificial synaesthesia, the third form, is characterised by deliberate associations (T. L. Hubbard, 1996):

1. Developmental synaesthesia: innate or developmental, and without known aetiology.

2. Acquired synaesthesia: caused by neuronal degeneration, cerebral or spinal cord lesion, temporal lobe epilepsy, release hallucinations, sensory deprivation, meditative focus, environmental conditions such as elevated levels of stress, or through the consummation of psychoactive drugs.

3. Artificial synaesthesia: such as artistic metaphor and learnt associations. 


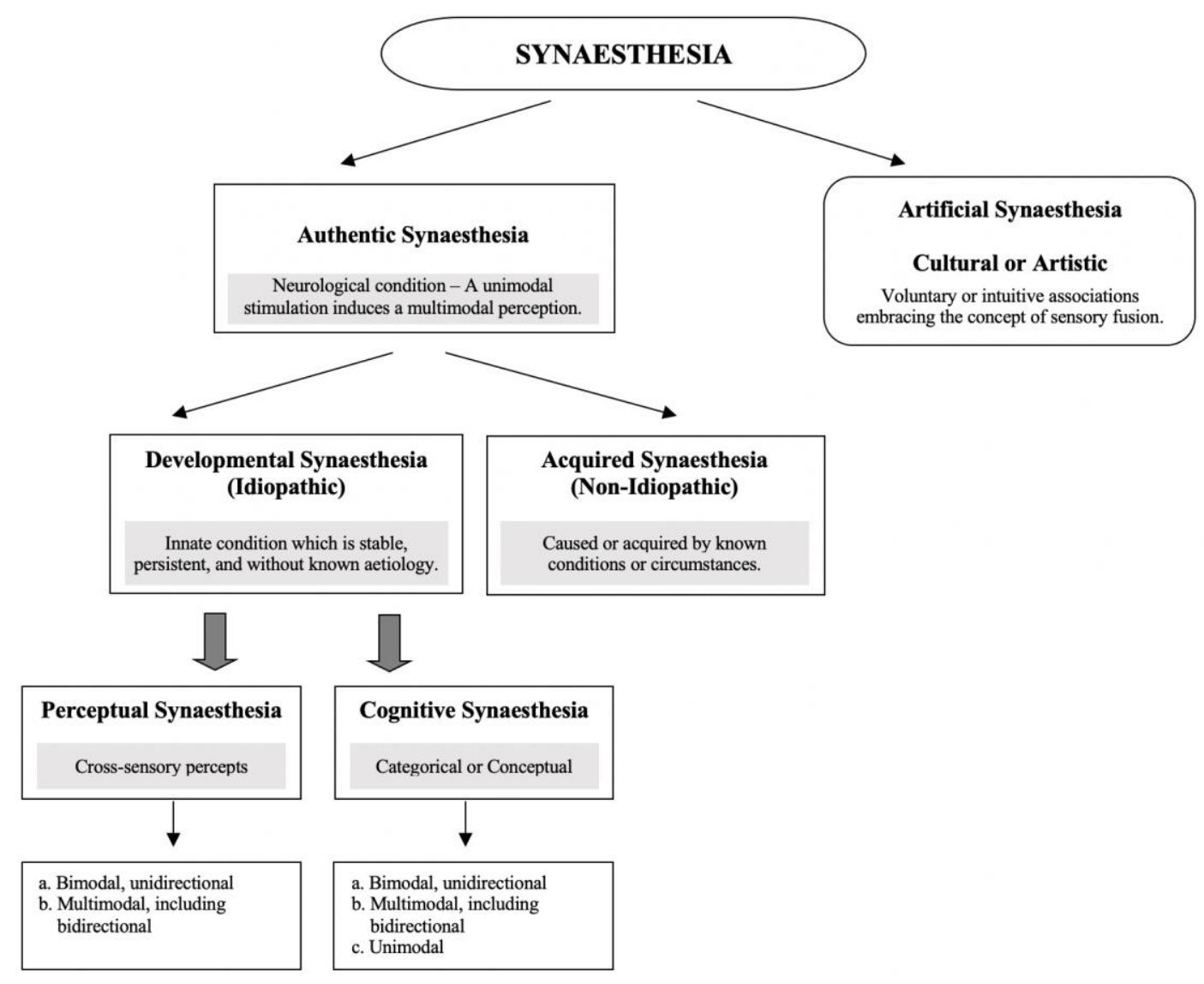

Figure 1. Graphic representation of the different forms of synaesthesia (author depiction).

Notwithstanding the richness of synaesthetic experiences outlined in Figure 1, the focus of this article is on cases of developmental synaesthesia: a rare neurological condition in which the stimulation of one sensory or cognitive pathway leads to an automatic, involuntary experience in a second sensory or cognitive pathway. As such, the stimulation of one sense modality automatically triggers a sensorial perception in another modality, which occurs in the absence of the direct stimulation of this second modality (BaronCohen \& Harrison, 1999). The triggering stimulus is known as the inducer, while the resultant synaesthetic experience is referred to as the concurrent (Grossenbacher, 1997). Although it is referred to as a neurological condition, synaesthesia does not generally interfere with normal functioning, and this label is more a reflection of the neurological basis of the perceptual differences that characterise synaesthesia, in a similar manner to AP.

People with synaesthesia are referred to as synaesthetes, and the range and variety of their experiences is vast. For example, a synaesthete may perceive numbers and letters as coloured (known as grapheme-colour synaesthesia), or perceive musical pitches as having 
distinct flavours (musical note-flavour synaesthesia). Learnt semantic categories such as letters, numbers, or days of the week are the most frequent stimuli (Hochel \& Milán, 2008), which then lead to sensory experiences such as the perception of synaesthetic colour or flavour (Hochel \& Milán, 2008).

\section{Absolute Pitch}

$\mathrm{AP}$ is the ability to label or produce a note of a given pitch in the absence of a reference note, with AP possessors providing pitch labels rapidly and effortlessly (Deutsch, 2013). AP is alternatively known as perfect pitch, although the label "perfect" is misleading as AP abilities are present in varying degrees among individuals (Deutsch, 2013; Miyazaki, 1988; Takeuchi \& Hulse, 1991; Wilson et al., 2009). AP is distinguishable from relative pitch (RP), which is a common ability learnt through musical training, in which the pitch of a tone is inferred by comparing it to an external reference tone (Theusch et al., 2009). Because many historical musical talents, such as Wolfgang Amadeus Mozart, are known to have been AP possessors, it is often regarded as an extremely desirable trait, or even as a "musical gift" that only occurs in exceptionally gifted individuals (Gagné \& McPherson, 2016; W. D. Ward, 1999).

\section{Classification}

\section{Synaesthesia}

There are two distinct types of developmental synaesthesia: Perceptual synaesthesia describes perceptions in which the inducers are sensory stimuli (such as sound), while in cognitive synaesthesia, the concurrents are induced by perceiving particular concepts (such as numbers; Grossenbacher \& Lovelace, 2001; Robertson \& Sagiv, 2005). Questions arise, however, as to the exact role of high-order cognition in the synaesthetic inducers. Initial studies undertaken to address this question have examined cases of grapheme-colour synaesthesia and observed that although there are documented exceptions, it does appear that the majority of synaesthetes are insensitive to variations of the form of individual graphemes and are therefore processing the linguistic function of the grapheme (Grossenbacher \& Lovelace, 2001; Smilek et al., 2002). 
In cognitive synaesthesia, there is the possibility that certain forms of synaesthesia may be unimodal, that is, that both the inducer and the concurrent belong to the same sense (such as in grapheme-colour synaesthesia, as has been previously established).

Nevertheless, and as depicted in Figure 1, there are also two other subclassifications that can be applied to both perceptual and cognitive

synaesthesia: bimodal and multimodal forms.

Bimodal synaesthesia is a unidirectional crossing of two sensory or cognitive pathways (e.g., auditory-visual, but not the inverse), while multimodal synaesthesia is the term used to describe the crossing of three or more sensory or cognitive pathways (such as when specific musical sounds induce not only colours, but odours as well for the same synaesthete). In rare multimodal cases, synaesthetes can experience truly eclectic sensorial experiences. Note also that all bidirectional forms of synaesthesia, such as when musical tones not only induce colours but inversely when colours induce musical tones for the same synaesthete, are classified as types of multimodal synaesthesia and are thus differentiated from bimodal synaesthesia. Bidirectional synaesthesia is highly unusual and equally a rare occurrence (Schönenberger \& Burela, 2007).

\section{Absolute Pitch}

AP possessors have been classified according to the extent of their AP ability. In a largescale survey of music students, Baharloo et al. (1998) developed a simple computer-based acoustical test that allowed them to subdivide AP possessors into four distinct groups. Individuals who were able to label any pitch regardless of timbre and spectral region were termed AP1 possessors. Individuals who performed at a significantly above-chance level, but who performed at a lower level for pure tone labelling than AP1 possessors, were termed AP2 or AP3 possessors, determined by the distribution of scores. AP4, the fourth category, comprised possessors those whose pitch perception for pure tones was significantly lower than for individuals in the other three categories, although their pitch perception for piano tones remained elevated.

In a separate study by Miyazaki (1990), subjects were classified into three subgroups according to their accuracy of response on an AP test. While all subjects were classified as AP possessors, the subgroups were obtained based on their accuracy of response: Group A obtained $>90 \%$ accuracy, Group B obtained 70\%-90\% accuracy, while Group C obtained $<70 \%$ accuracy. These results suggest that the accuracy of pitch identification is 
significantly different among different pitch classes, with this difference of identification accuracy being the most pronounced in Group C. For subjects in Group C, there was a highly significant effect of note category on their ability to correctly label pitch. Whitekey notes (without accidentals) were correctly identified at a level comparable to that of Group B, whereas their ability to correctly label black-key notes (notes with accidentals) was markedly inferior. This effect was moderately significant for Group B, but only marginally significant for Group A. This improvement in performance on an AP test for white-key notes was equally observed in a previous study by Miyazaki (1988).

To date, no consensus on a standardised classification system for AP has been reached; there is no universally accepted accuracy of response cut-off, and no relationship between the various subgroup classification systems that have been developed.

\section{Prevalence}

\section{Synaesthesia}

Synaesthesia is a relatively rare condition. Historical estimates based on self-report measures of the prevalence of synaesthesia varied widely. More recently, the first random sampling study on the condition estimated synaesthesia to occur in as high as $4.4 \%$ of the population (Simner, Mulvenna, et al., 2006). There are currently more than 80 documented forms of synaesthesia, with the most prevalent form being grapheme-colour synaesthesia. Evidence shows that between $82 \%$ and $88 \%$ of all forms of synaesthesia are triggered by language units such as graphemes, phonemes, and words (Niccolai et al., 2012; Simner, Glover, et al., 2006; Simner, Mulvenna, et al., 2006). The second most prevalent form is spatial-sequence synaesthesia, whereby time-related words are perceived in a spatial location, and this has been found to occur in up to $62 \%$ of cases (Niccolai et al., 2012).

The best-known music inducing form is music-colour synaesthesia, in which a musical stimulus (the inducer) elicits a colour perception (the concurrent). This type of truly crossmodal linking is often considered a paradigmatic example of synaesthesia, even though it is less common than other types. Estimations on the prevalence of music-colour synaesthesia within the synaesthete population vary between studies, being reported at $41 \%$ in a recent study by Niccolai et al. (2012), which is higher than the $25 \%$ and $18.7 \%$ 
reported by Rich et al. (2005) and Barnett et al. (2008), respectively. Sound-colour synaesthesia (non-musical) is also quite common and has been found to occur in $33 \%$ of synaesthetic occurrences (Niccolai et al., 2012). As becomes obvious with these estimates, it is common for synaesthetes to experience two or more types of synaesthesia, with one report showing that this occurs in approximately $81 \%$ of the synaesthetic population (Niccolai et al., 2012).

\section{Absolute Pitch}

The prevalence of AP in the general population is unknown. It is frequently cited in the literature as being estimated to occur in less than 1 in 10,000 , or $0.01 \%$ of the general population (Bachem, 1955); however, this estimate, regardless of the prevalence of its citation, is not substantiated by published data. More recent studies have focused on the prevalence of AP in musician subgroups, with data gathered from these international studies suggesting rates in these subgroups ranging from $4 \%$ to $65 \%$, with variations attributed to factors including genetic, ethnic, and/or language backgrounds, as well as the age of onset of musical training (Deutsch et al., 2006; Leite et al., 2016; Miyazaki et al., 2012. For an overview, see Carden \& Cline, 2019). Regardless of the population studied, the rarity of AP is perplexing, leading to suggestions that the lack of AP is analogous to colour anomia, in which patients can discriminate between colours, but are unable to associate them with verbal labels (Deutsch, 2013).

\section{Diagnosis/Test}

\section{Synaesthesia}

Historical reports of synaesthesia relied on case study descriptions; however, efforts in the 1980s to study synaesthesia objectively led to the development of measures of test-retest consistency (Baron-Cohen et al., 1987). Indeed, the consistency of concurrents measured over long time intervals is the behavioural gold standard assessment for detecting synaesthesia (e.g., Simner, Mulvenna et al., 2006). More recently, the effectiveness of single session tests of consistency in identifying synaesthetes have been validated, by comparing them to established longer retesting methods (Carmichael et al., 2015). Indeed, consistency testing may not be able to reliably identify every type of synaesthesia, nor every type of synaesthete (Simner, 2012), and for this reason, personal reports from 
synaesthetes should be used with measurements where appropriate (Ward, 2013). Certain music-induced forms of synaesthesia, such as tone-colour or instrument timbre-colour, are able to be tested using standardised online diagnostic tools (Eagleman et al., 2007); however, many forms of music-induced synaesthesia (such as those induced by stylistic or genre characteristics, or those for which the concurrent is not colour) still rely on selfreport methods.

\section{Absolute Pitch}

The previous discussion of the classification of AP possessors highlights the variance that exists within the classification process. Beyond outlining different ways in which AP possessors can be classified, it demonstrates that there is a lack of consensus in the field as to what does (or perhaps more importantly what does not) classify as a benchmark for AP possession. Indeed, while the pitch-labelling ability of AP possessors is generally recognised as its behavioural manifestation, different identification methods and criteria have been used in research studies, and no consensus has been reached as to the criteria to be applied to its identification (Sergeant \& Vraka, 2014).

AP tests usually consist of a series of piano and/or pure tone notes being played to participants with no feedback and no ability to check responses (Baharloo et al., 1998; Miyazaki, 1988, 1990). The time lapse between notes, the length of notes played, the number of notes, and the delivery of those notes vary between studies. Some tests are performed face to face (Baharloo et al., 1998; Deutsch et al., 2006, 2009; Wilson et al., 2012), while others are completed online (Athos et al., 2007; Bermudez \& Zatorre, 2009). Importantly, the reliability of online tests is open to scrutiny, given that there is no reliable way of assuring no aides are used during the test (such as having a keyboard or tuning device at the participants immediate disposal).

\section{Synaesthesia, AP, and Music Perception}

\section{Synaesthesia}

In addition to the prevalence of synaesthesia within the general population, the reported high incidence of synaesthesia among artistic professionals and people with creative hobbies is an additional demographical aspect that was confirmed in the previously 
mentioned large-scale study by Rich et al. (2005). It must be noted, however, that Rich and colleagues did not suggest causality in their study, stating

Having synaesthesia may predispose one toward being artistic; alternatively, people with an artistic predisposition may be more likely to have synaesthesia. It is also possible that some other factor or set of factors, as yet unknown, may influence the development of both synaesthesia and artistic talents. (p. 78)

These researchers did, however, establish that $24 \%$ of the synaesthetes they questioned were professionally engaged in the arts, as compared to a general population rate of only 2\% (Hochel \& Milán, 2008). Other studies have also shown similar results (Cytowic, 1989; Domino, 1989; Niccolai et al., 2012; Ramachandran \& Hubbard, 2001b). A study of arts students found that $7 \%$ of the sample were synaesthetes, compared to $2 \%$ of the control sample (Rothen \& Meier, 2010), suggesting that synaesthesia may be more prevalent in arts students, thus tying in with previous research into the higher prevalence of arts professionals within the synaesthete population. These studies have led to suggestions as to the possible links between synaesthesia, metaphor, creativity, and the origins of language (Domino, 1989; Ramachandran \& Hubbard, 2001b; Sitton \& Pierce, 2004). Apart from professional engagement, Niccolai et al. (2012) further indicated that $68 \%$ of the respondents in their study were artistically active, and an interest in the arts was frequently reported. Interestingly, $78 \%$ of participants in this study indicated that their synaesthesia was an advantage in creative jobs, memorising, learning, or calculating. Participants further described themselves as skilled at painting, learning, foreign languages, and memorisation but poor in their abilities in mathematics, tasks involving sustained concentration, spatial imagination, and spatial perception.

Apart from general studies of synaesthesia, creativity, and artistic ability, there is a paucity of published studies that have specifically examined the influence of synaesthesia on music perception, musical development, or musical abilities. One possible explanation for this absence is that while the semiotics of graphemes and similar symbols are widely known and accepted among the general population, the study of synaesthesia and music would require a high level of understanding of musical terminology by both the researchers and the synaesthetes themselves. Furthermore, the paucity of research into music-colour synaesthesia may also be attributable to the ongoing focus on tone-colour synaesthesia, to the detriment of other forms of music-induced synaesthesia such as those elicited by instrument, timbre, tonality, genre, or compositional style. 


\section{Absolute Pitch}

AP ability is often synonymously linked to enhanced low-level auditory abilities. Yet experimental studies using pitch discrimination tasks have not confirmed this assertion but rather show no difference in performance on tasks between AP possessors and nonpossessors (Fujisaki \& Kashino, 2002; Siegel, 1972). However, performance of AP possessors on tasks related to high-level pitch processing differs from the performance of non-possessors. The potential for AP to enhance or detract from specific musical abilities is, however, situationally dependent. Indeed, there are four key areas where this has been demonstrated: The first three indicate enhanced musical ability, while the fourth suggests a potentially negative effect of AP possession:

1. Pitch memory. Possessors of AP perform better on certain pitch memory tasks (Bachem, 1954; Rakowski \& Rogowski, 2007; Siegel, 1974) such as being able to indicate, after a 1-week interval, whether a standard tone and a comparison tone are the same or different (Bachem, 1954). This is because they are able to assign verbal labels to pitch classes, due to their refined abilities to apply a verbal encoding strategy (Bachem, 1954; Rakowski \& Rogowski, 2007; Siegel, 1974).

2. Musical dictation. AP musicians are able to undertake musical dictation (notating a musical passage while hearing it) far more easily than non-possessors, irrespective of age, onset of musical training or even years of musical training (Dooley \& Deutsch, 2010).

3. Interval identification. AP possession is positively associated with interval identification tasks requiring only RP (Dooley \& Deutsch, 2011).

4. RP processing. AP possessors may be at a disadvantage in certain distinct situations where RP processing is required. One example is when music is transposed, or when AP possessors hear music played in a different key to the written score they are reading (Deutsch, 2013). Absolute pitch ability is therefore not always advantageous to musical activities, particularly in situations where the AP possessor needs to transpose music (Mito, 2003).

\section{The Co-occurrence of Synaesthesia and AP}

Synaesthesia and AP are two uncommon cognitive conditions that have been anecdotally reported to occur together in individuals (Bernard, 1986; Gregersen et al., 2013; Hänggi 
et al., 2008). While the co-occurrence of synaesthesia and AP in professional musicians has been noted in case studies (Bernard, 1986), research into the relationship that exists between these two conditions is recent, with only six known studies having addressed this subject (see Table 2). In the following section, these six studies are discussed in chronological order.

Table 2. Summary results for six studies that examine the relationship between synaesthesia and absolute pitch.

\begin{tabular}{|c|c|c|c|c|}
\hline & Participants & $\begin{array}{l}\text { Synaesthesia } \\
\text { Type }\end{array}$ & $\begin{array}{l}\text { Methodology/ } \\
\text { Modality }\end{array}$ & Results \\
\hline Ward 2006 & $\begin{array}{l}10 \\
\text { synaesthetes } \\
10 \text { controls }\end{array}$ & Sound-colour & $\begin{array}{l}\text { Colour } \\
\text { consistency } \\
\text { tests }\end{array}$ & $\begin{array}{l}\text { Suggestion that an } \\
\text { acquired cognitive } \\
\text { form of AP is } \\
\text { possible if four } \\
\text { separate conditions } \\
\text { are met. }\end{array}$ \\
\hline Hänggi 2008 & $\begin{array}{l}1 \text { synaesthete } \\
\text { with AP }\end{array}$ & $\begin{array}{l}\text { Multiple forms, } \\
\text { including } \\
\text { musical interval- } \\
\text { taste and tone- } \\
\text { colour }\end{array}$ & $\begin{array}{l}\text { Neuroanatomic } \\
\text { al case study }\end{array}$ & $\begin{array}{l}\text { Large structural } \\
\text { differences in the } \\
\text { auditory cortices, } \\
\text { gustatory and visual } \\
\text { areas; a reduction in } \\
\text { grey matter volume } \\
\text { in auditory areas. }\end{array}$ \\
\hline Loui 2012 & $\begin{array}{l}15 \\
\text { synaesthetes } \\
15 \mathrm{AP} \\
\text { possessors } \\
30 \text { controls }\end{array}$ & Tone-colour & fMRI & $\begin{array}{l}\text { Both shared and } \\
\text { distinct neural } \\
\text { enhancements in } \\
\text { synaesthesia and } \\
\text { AP. }\end{array}$ \\
\hline $\begin{array}{l}\text { Gregersen } \\
2013\end{array}$ & $\begin{array}{l}151 \\
\text { synaesthetes } \\
768 \mathrm{AP} \\
\text { possessors }\end{array}$ & Multiple forms & $\begin{array}{l}\text { Survey; } \\
\text { Combined } \\
\text { linkage } \\
\text { analysis }\end{array}$ & $\begin{array}{l}\text { Close phenotypic } \\
\text { and genetic } \\
\text { relationship between } \\
\text { synaesthesia and } \\
\text { AP. }\end{array}$ \\
\hline Itoh 2018 & $\begin{array}{l}33 \\
\text { synaesthetes } \\
15 \mathrm{AP} \\
\text { possessors }\end{array}$ & $\begin{array}{l}\text { Pitch class- } \\
\text { colour }\end{array}$ & $\begin{array}{l}\text { Synaesthesia } \\
\text { and AP battery } \\
\text { tests }\end{array}$ & $\begin{array}{l}\text { AP possession is not } \\
\text { an essential } \\
\text { component of pitch } \\
\text { class-colour } \\
\text { synaesthesia. }\end{array}$ \\
\hline Lebeau 2021 & $\begin{array}{l}1 \text { synaesthete } \\
\text { with AP }\end{array}$ & Tone-colour & $\begin{array}{l}\text { Synaesthesia } \\
\text { test and } \\
\text { interview (AP } \\
\text { untested) }\end{array}$ & $\begin{array}{l}\text { Synaesthetic colour } \\
\text { cues can be } \\
\text { harnessed to learn } \\
\text { new pitch } \\
\text { associations in } \\
\text { baroque tuning. }\end{array}$ \\
\hline
\end{tabular}


Study 1: Ward et al. (2006)

Intriguing parallels between sound-colour synaesthesia and AP were the focus of a study of 10 sound-colour synaesthetes and 10 controls aimed at investigating how different aspects of an auditory stimulus are mapped on to the visual domain in both synaesthetes and controls (Ward et al., 2006). As has been hypothesised with synaesthesia, results suggest that AP could be an outcome of neural pruning (Keenan et al., 2001) and that all infants may be born with the ability (W. D. Ward, 1999). Furthermore, and although none of the study participants reported this ability, questions remain as to whether sound-colour synaesthetes can use their colour percepts in order to deduce the identity of a note, and thus acquire a cognitive form of AP ability (Ward et al., 2006). If this possibility is valid, then four separate conditions would be necessary for this to occur: that notes a semitone apart must have perceivable differences in colour; that the context in which the note is played (such as the instrument playing the note) would not modify the colour percept; that the perceptual differences can be committed to long-term memory; and finally, that these stored perceptual differences can acquire linguistic labels (Ward et al., 2006).

Study 2: Hänggi et al. (2008)

A neuroanatomical case study of a professional musician with AP and multiple forms of synaesthesia demonstrates that the auditory cortical regions of the synaesthete musician brain differ significantly from those typically found in non-synaesthete musicians (Hänggi et al., 2008). The synaesthete documented in this study, ES, is a professional musician with AP, musical interval-taste synaesthesia, and tone-colour synaesthesia. In 2005, the case of ES's interval-taste synaesthesia became the first documented case of this form of synaesthesia (Beeli et al., 2005). During the 2008 study by Hänggi and colleagues, ES and the control groups (20 females and 17 female musicians - 10 of whom were AP possessors) were tested for both diffusion tensor imaging (DTI) and T1 images. As hypothesised, large structural differences were revealed between the brain of ES and those of the controls, in the auditory cortices, and in the gustatory and visual areas. These results suggest a neuroanatomical basis of synaesthetic experiences for the two types of synaesthesia experienced by ES. Surprisingly, the results also demonstrated a reduction in grey matter volume in auditory areas of ES's brain, which was unexpected in musicians with AP (Luders et al., 2004). It was concluded, as by her own admission, that this female musician uses her tone-colour synaesthesia to identify the pitch of a tone and that this cognitive problem-solving mechanism rendered a reorganisation of her auditory areas 
unnecessary (Hänggi et al., 2008). While this was a thorough case study analysis, the critical comparison with musicians with AP was not conclusive, and it is therefore possible that the differences found were related to AP, and not synaesthesia (Hupé \& Dojat, 2015).

Study 3: Loui et al. (2012)

The degree to which neural substrates recruited for music listening may be shared between synaesthetes and AP possessors was the focus of a neuroimaging study by Loui et al. (2012). In a sparse-sampled functional magnetic resonance imaging study, 15 tone-colour synaesthetes, 15 AP possessors, and 30 matched controls were asked to rate the perceived levels of arousal of selected musical excerpts. Results support both shared (for the early cortical processing of music compared to non-APs and non-synaesthetes) and distinct neural enhancements (distinct patterns of functional activations for perceptual associations, categorisations, and affective processing) in AP and tone-colour synaesthesia. Furthermore, a survey was administered to all subjects to assess their linguistic and musical background. The common enhancements revealed in early cortical mechanisms of perceptual analysis, followed by relative specialisation in later association and categorisation processes, support the unique behaviours of synaesthetes and AP possessors during music listening.

Study 4: Gregersen et al. (2013)

There is a significantly higher prevalence of synaesthesia in populations of AP possessors. In a survey by Gregersen et al. (2013), the occurrence of synaesthesia in a population of 768 subjects with documented AP was evaluated. Of the 768 AP possessors, 151 (20.1\%) reported being synaesthetes with colour being the most common concurrent. This is significantly more than the highest estimated prevalence rate of $4.4 \%$ in the general population (Simner, Mulvenna, et al., 2006). A combined linkage analysis of 53 multiplex families with AP and 36 multiplex families with synaesthesia was undertaken, with the results demonstrating a close phenotypic and genetic relationship between AP and synaesthesia. While this study was unable to definitively establish the identity of a causative gene or genes involved in the neurodevelopment of AP and synaesthesia, it did provide a formal analysis of the anecdotally reported proposition that AP and synaesthetic experiences may occur together. Furthermore, Gregerson and colleagues noted the higher occurrence rate of AP and synaesthesia in subjects with autism spectrum disorder and 
proposed that defining the genetic basis of AP and synaesthesia may provide insights into the genetics and neurobiology of autism spectrum disorder.

\section{Study 5: Itoh and Nakada (2018)}

In cases of pitch class-colour synaesthesia, individual musical notes induce colour percepts. To explore the behavioural features and mechanisms underlying this form of synaesthesia, Itoh and Nakada (2018)examined whether AP possession was an essential component of this form of synaesthesia. Behavioural measures of 33 self-reported synaesthetes, of whom 15 were also reported as possessing AP. Results suggest that AP is not a necessary condition to the possession of pitch class-colour synaesthesia, as the overall colour changes across the pitch classes ( $d o-t i$ in solfège) resembled hues of the colours of the rainbow for all 33 participants with self-reported synaesthesia. As synaesthetic percepts are characterised by their idiosyncrasy, this systematic rainbow configuration and the striking heterogeneity of results are atypical for synaesthesia and suggest that the participants in this study were relying on learnt associations, rather than experiencing true synaesthetic percepts. Furthermore, this premise is questionable, given that all participants were classified as either "high" or "low" AP possessors and a control group of non-AP possessors was not identified. In brief, it remains unclear whether the participants were indeed idiopathic synaesthetes, and what the role of their varying levels of AP possession was within this diagnosis.

Study 6: Lebeau et al. (2021)

The degree to which new synaesthetic pitch-colour associations could be developed through training was explored in a case study analysis of a professional violinist with both tone-colour synaesthesia and AP (Lebeau et al., 2021). The musician in this study, NTM, experienced a serious incongruence in her synaesthetic percepts when she switched from modern tuning $(\mathrm{A}=440 \mathrm{hz})$ to baroque tuning $(\mathrm{A}=415 \mathrm{hz})$ when playing the violin and reported that this incongruence severely interfered with her musical performance. Using synaesthetic colour cues to scaffold her training enabled her to learn new pitch associations in baroque tuning that cancelled any interference while performing. A mixedmethods approach was used to evaluate NTM's synaesthetic experience, including standardised consistency tests for synaesthesia and a semi-structured interview. It is worth noting, therefore, that no AP tests were reported in the methods section and that NTM's 
AP appears to have been taken at face value. The extent of her actual AP ability is therefore unknown.

\section{Discussion}

The aim of this review was to investigate the potential relationship between synaesthesia and AP for musicians who possess both conditions by systematically comparing the definitions, classifications, prevalence, diagnoses, and impacts on music perception of synaesthesia and AP and providing insights into the varying states of the literature and knowledge of both conditions. While the relationship between tone-colour synaesthesia and AP is frequently noted, any interaction between these two conditions remains highly speculative and lacking empirical foundation. Indeed, the classification and characteristics of both conditions is less than straightforward, precisely because the diagnostic criteria for each condition are ambiguous. In the case of synaesthesia, previous studies have noted that the term signifies and describes different notions, realities, and perspectives and is therefore highly context specific. Of note in this classification is the distinction between perceptual and cognitive synaesthesia, which is of relevance for our understanding of AP. For synaesthetes with tone-colour synaesthesia (or other tone-induced forms of synaesthesia), it is unclear whether it is the perceived tone or the interpreted pitch class (the set of all pitches related by an octave, e.g., all "C's" or all "B flat's") that elicits their synaesthetic percepts. The concept of pitch class-colour synaesthesia in relation to AP was discussed by Itoh and Nakada (2018); however, as has been previously mentioned, it is unclear in this instance whether study participants were relying on learnt associations or experiencing genuine synaesthetic colour percepts. Further research into the underlying perceptual and cognitive mechanisms of both conditions is therefore warranted.

One commonality between synaesthesia and AP is that both exhibit similar definitional irregularities that focus on whether they are all-or-nothing conditions or whether they lie along a continuum. The debate as to whether they are dimensional or categorical constructs is, however, an open one. In the field of synaesthesia research, there is evidence to suggest a continuum of the strength of colour-vowel (Cuskley et al., 2019) and pitchsize (Bien et al., 2012) associations as reported by non-synaesthetes. These findings suggest a distribution of structured cross-modal associations in the general population and 
provide evidence for the viewpoint that synaesthesia exists at the extremity of a spectrum of normal perceptual processes. This viewpoint is, however, contended, with Ward (2019) arguing that the phenomenology and causal mechanisms of synaesthesia are unique and that synaesthesia is likely to be associated with a distinct neurocognitive profile. Similarly, AP is often categorised as a binary, all-or-nothing trait, such as by Athos et al. (2007) who conducted a web-based large sample study ( $n=2,213$ participants, $n=981$ with AP). The bimodal distribution of results supports the categorisation of AP as a dichotomous and distinct perceptual trait. Despite these findings, analyses of behavioural performance suggest that the trait exists along a continuum, with growing evidence to support this claim. For example, in a study by Bermudez and Zatorre (2009), AP possessors and non-possessors were recruited within a population of musically trained subjects and tested for AP ability. The performance of a substantial number of subjects fell between the AP threshold and chance (1/12, or approximately $8 \%$ correct responses). In a separate study by Deutsch et al. (2009), 176 students at the University of Southern California were tested for AP ability. These subjects were tested in class and were not self-selected. The majority of students obtained scores that were consistent with chance, although a substantial proportion of students received scores that were above chance, yet below the cut-off criteria for AP. It has therefore been suggested that in less developed forms of AP where pitch-labelling only occurs for specific musical notes, participants may be reliant on a range of auditory cues (such as timbre, notes with or without accidentals, and pitch register), with these limited AP templates being more bound to contextual cues present during perceptual encoding (Wilson et al., 2012). It is therefore possible to conjecture that various forms of music-induced synaesthesia may also rely on a range of auditory cues that could impact the degree or strength of synaesthesia experienced.

The inconsistencies of diagnostic and definitional criteria have given rise to difficulties in assessing the prevalence of both conditions. Indeed, while inconsistencies in assessment methodology, criteria, and population studies have produced wide variations in prevalence estimates of AP, and while this makes it difficult to compare the prevalence of AP to that of synaesthesia, both conditions are generally thought to occur rarely within the general population. One important exception to this general prevalence rate is in the population of people with autism, as both synaesthesia and AP have been demonstrated as occurring more often in this population. Although the general prevalence rate for synaesthesia is suggested to be at 4\% (Simner et al., 2006; Simner, Mulvenna, et al., 2006), approximately $20 \%$ of people with autism have synaesthesia (Baron-Cohen et al., 2013; Neufeld et al., 2013). While the prevalence of AP in the general population is 
unknown, AP is suggested to occur in between $5 \%$ and $11 \%$ in people with autism (DePape et al., 2012; Rimland \& Fein, 1988) and is consistently observed among savant autistic musicians (for a review, see Mottron et al., 2013). Furthermore, the relationship between synaesthesia and autism spectrum conditions appears to be more specifically linked to the presence of savant skills (Hughes et al., 2017). A discussion on the interplay of synaesthesia, AP, and autism, and their possible mechanisms, is timely. This is however, beyond the scope of this review.

One key difference in the scope of literature pertaining to synaesthesia and AP concerns their influence on music perception, or musical development or abilities. While general studies on the relationship between synaesthesia and creativity have been conducted (Cytowic, 1989; Domino, 1989; Niccolai et al., 2012; Ramachandran \& Hubbard, 2001b; Rich et al., 2005; Rothen \& Meier, 2010; Sitton \& Pierce, 2004), there is a lack of studies that have specifically investigated the influence of synaesthesia on music perception, musical development, or abilities. In contrast, several comprehensive studies have explored the impact of AP on specific musical abilities, including pitch memory, melodic dictation, interval identification, and RP processing (Bachem, 1954; Deutsch, 2013; Dooley \& Deutsch, 2010, 2011; Mito, 2003; Rakowski \& Rogowski, 2007; Siegel, 1974). Furthermore, the co-occurrence of synaesthesia and AP has been anecdotally noted in case studies of professional musicians. More specifically, six articles addressing the relationship between synaesthesia and AP from behavioural, neurological, and genetic perspectives have been reported (Gregersen et al., 2013; Hänggi et al., 2008; Itoh \& Nakada, 2018; Lebeau et al., 2021; Loui et al., 2012; Ward et al., 2006). In reviewing the literature, however, no data have been found on the association between synaesthesia and AP in music perception, performance, or other musical contexts. All six of the studies surveyed here report the co-occurrence of synaesthesia and AP focused on tone-colour synaesthesia. The comparison between the hypothesised mechanisms of AP and the ability to assign note labels has therefore focused exclusively on synaesthetes who reported colour percepts elicited by pure tones, thus omitting other potential aspects of musicinduced forms of synaesthesia such as timbre, tonality, and context. This may in part explain why the important gap of linking AP to synaesthesia has not to date been adequately explored. 


\section{Conclusion}

This article began by asking what it might be like, from the perspective of nonsynaesthetes and AP possessors, to be able to experience these two conditions. Throughout musical history, there have been an unknown number of pre-eminent composers such as W. A. Mozart, Olivier Messiaen, Jean Sibelius, and Franz Liszt, who were synaesthetes and/or AP possessors. How might the possession of one, or indeed the interaction of both of these two conditions impacted their overall musical development, and in what ways might they be related to the legacy of creative works that they left Western civilisation? This critical issue highlights a substantial gap in music research: namely that neither synaesthesia nor AP has been adequately explored in terms of the above conceptions.

The previous sections of this article have established synaesthesia and AP as authentic and diagnosable conditions and confirmed that empirical testing can lead to insights into their impact on music perception. Two key issues remain largely unsolved in the existing literature. First, while the prevalence of synaesthesia has been established as higher among arts professionals and people involved in the creative industries (Ramachandran \& Hubbard, 2001b; Rich et al., 2005; Rothen \& Meier, 2010), and while synaesthesia is linked to enhanced memory and creativity (Domino, 1989; Ramachandran \& Hubbard, 2001b, 2003; Rich et al., 2005; Rothen et al., 2012; Sitton \& Pierce, 2004), to date, no published studies have examined the impact of music and sound-induced forms of synaesthesia on musical development. Indeed, auditory related forms of synaesthesia are commonly referred to as epitomising the cross-sensory aspect of certain forms of synaesthesia. Yet ordinal forms of synaesthesia, such as grapheme-colour synaesthesia, are by far the most widely studied (Hubbard, 2007), with contemporary research habitually neglecting other forms of synaesthesia. There is thus currently a paucity of literature that examines music or auditory-related forms of synaesthesia, leading Meier and Rothen (2015) to explicitly call for future studies to address "the development of other forms, for example, sound-colour synaesthesia" (p. 2). It is possible that this gap in current synaesthesia research might be explained by music's inherent complexity, as well as the perceived difficulty of recruiting participants with a high level of music language competence. It is also noteworthy that in the limited number of studies on music-induced forms of synaesthesia, there is a strong focus on tone-colour synaesthesia to the detriment of other forms. Second, while studies on the influence of AP on specific musical abilities have been undertaken, there remains a deficiency of studies that investigate the effects of 
AP on a possessor's motivation to continue musical studies, their affective response to their condition, or general cognitive benefits. Future research is therefore needed to elucidate the extent to which the possession of these two conditions impacts musical development more generally.

In addition, while the co-occurrence of certain types of music-induced synaesthesia and AP has been noted (Gregersen et al., 2013; Hänggi et al., 2008; Lebeau et al., 2021), any interaction between these two conditions, or indeed with other conditions such as autism, remains highly speculative and lacking empirical foundation. A key priority for future research within the domain of music is therefore to assess the interaction of these two conditions and various forms of musical ability and potential.

Much remains to be revealed about the lived experience of performing and interacting with music, particularly in terms of how those who possess synaesthesia and AP function when working creatively, how they refine and develop their musical expertise, and how such information might enable us to develop more robust explanations of prodigiousness, giftedness, and musical talent. Accepting the view that "nature reveals herself through exceptions" (Cytowic \& Eagleman, 2011, p. 246) allows us to view synaesthesia and AP as not simply "fascinating" conditions, but rather as a means by which to highlight the idiosyncrasy of each of our subjective perceptions of music. In these ways, studying the impact of synaesthesia and AP on music perception may provide a number of fresh insights into these two conditions, their interaction, and what they might reveal about the musical experience more generally.

\section{Declaration of Conflicting Interests}

The author(s) declared no potential conflicts of interest with respect to the research, authorship, and/or publication of this article.

\section{Funding}

The author(s) received no financial support for the research, authorship, and/or publication of this article.

\section{ORCID iD}

Solange Glasser https://orcid.org/0000-0002-2630-6118 


\section{References}

Athos, E. A., Levinson, B., Kistler, A., Zemansky, J., Bostrom, A., Freimer, N. (2007). Dichotomy and perceptual distortions in absolute pitch ability. Proceedings of the National Academy of Sciences, USA, 104, 14795-14800.

Bachem, A. (1954). Time factors in relative and absolute pitch determination. Journal of the Acoustical Society of America, 26, 751-753.

Bachem, A. (1955). Absolute pitch. The Journal of the Acoustical Society of America, 27, 1180.

Baharloo, S., Johnston, P. A., Service, S. K., Gitschier, J., Freimer, N. B. (1998). Absolute pitch: An approach for identification of genetic and nongenetic components. American Journal of Human Genetics, 62, 224-231.

Barnett, K. J., Finucane, C., Asher, J. E., Bargary, G., Corvin, A. P., Newell, F. N., Mitchell, K. J. (2008). Familial patterns and the origins of individual differences in synaesthesia. Cognition, 106, 871-893.

Baron-Cohen, S., Harrison, J. (1999). Synesthesia: A challenge for developmental cognitive neuroscience. In Tager-Flusberg, H. (Ed.), Developmental cognitive neuroscience. Neurodevelopmental disorders (pp. 491-503). The MIT Press.

Baron-Cohen, S., Johnson, D., Asher, J., Wheelwright, S., Fisher, S. E., Gregersen, P. K., Allison, C. (2013). Is synaesthesia more common in autism? Molecular Autism,

4, 40. https://doi.org/10.1186/2040-2392-4-40

Baron-Cohen, S., Wyke, M. A., Binnie, C. (1987). Hearing words and seeing colours: An experimental investigation of a case of synaesthesia. Perception, 16, 761767. https://doi.org/10.1068/p160761

Beeli, G., Esslen, M., Jäncke, L. (2005). Synaesthesia: When coloured sounds taste sweet. Nature, $434,38$.

Bermudez, P., Zatorre, R. J. (2009). A distribution of absolute pitch ability as revealed by computerized testing. Music Perception, 27, 89-101.

Bernard, J. W. (1986). Messiaen's synaesthesia: The correspondence between color and sound structure in his music. Music Perception, 4, 41-68.

Bien, N., ten Oever, S., Goebel, R., Sack, A. T. (2012). The sound of size: Crossmodal binding in pitch-size synesthesia: A combined TMS, EEG and psychophysics study. NeuroImage, 59, 663-672. https://doi.org/10.1016/j.neuroimage.2011.06.095

Carden, J., Cline, T. (2019). Absolute pitch: Myths, evidence and relevance to music education and performance. Psychology of Music, 47, 890-901.

Carmichael, D. A., Down, M. P., Shillcock, R. C., Eagleman, D. M., Simner, J. (2015). Validating a standardised test battery for synesthesia: Does the synesthesia battery reliably detect synesthesia? Consciousness and Cognition, 33, 375385. https://doi.org/10.1016/j.concog.2015.02.001

Cuskley, C., Dingemanse, M., Kirby, S., van Leeuwen, T. M. (2019). Cross-modal associations and synesthesia: Categorical perception and structure in vowel-color mappings in a large online sample. Behavior Research Methods, 51, 1651-1675. https://doi.org/10.3758/s13428-01901203-7

Cytowic, R. E. (1989). Synesthesia: A union of the senses. Springer-Verlag.

Cytowic, R. E. (2002). Touching tastes, seeing smells—and shaking up brain science. Cerebrum, 4, 7-26.

Cytowic, R. E., Eagleman, D. M. (2011). Wednesday is indigo blue: Discovering the brain of synesthesia. MIT Press Ltd.

DePape, A.-M. R., Hall, G. B. C., Tillmann, B., Trainor, L. J. (2012). Auditory processing in highfunctioning adolescents with autism spectrum disorder. PLoS One,

7, e44084. https://doi.org/10.1371/journal.pone.0044084

Deutsch, D. (2013). Absolute pitch. In Deutsch, D. (Ed.), The psychology of music (3rd ed., pp. 141182). Elsevier. 
Deutsch, D., Dooley, K., Henthorn, T., Head, B. (2009). Absolute pitch among students in an American music conservatory: Association with tone language fluency. Journal of the Acoustical Society of America, 125, 2398-2403.

Deutsch, D., Henthorn, T., Marvin, E., Xu, H. (2006). Absolute pitch among American and Chinese conservatory students: Prevalence differences, and evidence for a speech-related critical period (L). Journal of the Acoustical Society of America, 119, 719-722.

Domino, G. (1989). Synesthesia and creativity in fine arts students: An empirical look. Creativity Research Journal, 2, 17-29. https://doi.org/10.1080/10400418909534297

Dooley, K., Deutsch, D. (2010). Absolute pitch correlates with high performance on musical dictation. Journal of the Acoustical Society of America, 128, 890 893. https://doi.org/10.1121/1.3458848

Dooley, K., Deutsch, D. (2011). Absolute pitch correlates with high performance on interval naming tasks. Journal of the Acoustical Society of America, 130, 40974104. https://doi.org/10.1121/1.3652861

Eagleman, D. M., Kagan, A. D., Nelson, S. S., Sagaram, D., \& Sarma, A. K. (2007). A standardized test battery for the study of synesthesia. Journal of Neuroscience Methods, 159(1), 139-145.

Fujisaki, W., Kashino, M. (2002). The basic hearing abilities of absolute pitch possessors. Acoustical Science and Technology, 23, 77-83.

Gagné, F., McPherson, G. E. (2016). Analyzing musical prodigiousness using Gagné's integrative model of talent development. In McPherson, G. E. (Ed.), Music prodigies: Interpretations from psychology, education, musicology and ethnomusicology (pp. 3-114). Oxford University Press.

Glasser, S. (2018). The Impact of Synaesthesia and Absolute Pitch on Musical Development. $\mathrm{PhD}$ Dissertation, University of Melbourne, Australia.

Glasser, S. (in press). Synesthesia and music performance. In McPherson, G. E. (Ed.), Oxford handbook of music performance. Oxford University Press.

Gregersen, P. K., Kowalsky, E., Lee, A., Baron-Cohen, S., Fisher, S. E., Asher, J. E., Ballard, D., Freudenberg, J., \& Li, W. (2013). Absolute pitch exhibits phenotypic and genetic overlap with synesthesia. Human molecular genetics, 22(10), 20972104. https://doi.org/10.1093/hmg/ddt059

Grossenbacher, P. G. (1997). Perception and sensory information in synesthetic experience. In Baron-Cohen, S., Harrison, J. (Eds.), Synesthesia: Classic and contemporary readings (pp. 148-172). Blackwell.

Grossenbacher, P. G., Lovelace, C. T. (2001). Mechanisms of synesthesia: Cognitive and physiological constraints. Trends in Cognitive Sciences, 5, 36-41.

Hänggi, J., Beeli, G., Oechslin, M. S., Jäncke, L. (2008). The multiple synaesthete E.S. Neuroanatomical basis of interval-taste and tone-colour synaesthesia. Neuroimage, 43, 192203.

Hochel, M., Milán, E. G. (2008). Synaesthesia: The existing state of affairs. Cognitive Neuropsychology, 25, 93-117.

Hubbard, E. M. (2007). Neurophysiology of synesthesia. Current Psychiatry Reports, 9, 193-199.

Hubbard, T. L. (1996). Synesthesia-like mappings of lightness, pitch, and melodic interval. The American Journal of Psychology, 109, 219-238.

Hughes, J., Simner, J., Baron-Cohen, S., Treffert, D., Ward, J. (2017). Is synaesthesia more prevalent in autism spectrum conditions? Only where there is prodigious talent. Multisensory Research, 30, 391-408. https://doi.org/10.1163/22134808-00002558

Hupé, J.-M., Dojat, M. (2015). A critical review of the neuroimaging literature on synesthesia. Frontiers in Human Neuroscience, 9, Article 103.

Itoh, K., Nakada, T. (2018). Absolute pitch is not necessary for pitch class-color synesthesia. Consciousness and Cognition, 65, 169-181.

Keenan, J. P., Thangaraj, V., Halpern, A. R., Schlaug, G. (2001). Absolute pitch and planum temporale. Neuroimage, 14, 1402-1408. 
Lebeau, C., Tremblay, M. N., \& Richer, F. (2020). Adaptation to a New Tuning Standard in a Musician with Tone-color Synesthesia and Absolute Pitch, Auditory Perception \& Cognition, 3(3), 113-123, DOI: 10.1080/25742442.2021.1886846

Leite, R. B., Mota-Rolim, S. A., Queiroz, C. M. (2016). Music proficiency and quantification of absolute pitch: A large-scale study among Brazilian musicians. Frontiers in Neuroscience, 10, 447. https://doi.org/10.3389/fnins.2016.00447

Loui, P., Zamm, A., \& Schlaug, G. (2012). Absolute Pitch and Synesthesia: Two Sides of the Same Coin? Shared and Distinct Neural Substrates of Music Listening. ICMPC:

Proceedings. International Conference on Music Perception and Cognition, 618-623.

Luders, E., Gaser, C., JäNcke, L., \&., \& Schlaug, G. (2004). A voxel-based approach to gray matter asymmetries. Neuroimage, 22, 656-664.

Meier, B., Rothen, N. (2015). Developing synaesthesia: A primer. Frontiers in Human Neuroscience, 9, 211. https://doi.org/10.3389/fnhum.2015.00211

Mito, H. (2003). Performance at a transposed keyboard by possessor and non-possessor of absolute pitch. Bulletin of the Council for Research in Music Education, 18(157), 1823. https://doi.org/10.2307/40319182

Miyazaki, K. (1988). Musical pitch identification by absolute pitch possessors. Perception \& Psychophysics, 44, 501-512.

Miyazaki, K. (1990). The speed of musical pitch identification by absolute-pitch possessors. Music Perception: An Interdisciplinary Journal, 8, 177-188. https://doi.org/10.2307/40285495

Miyazaki, K., Makomaska, S., Rakowski, A. (2012). Prevalence of absolute pitch: A comparison between Japanese and Polish music students. The Journal of the Acoustical Society of America, 132, 3484-3493. https://doi.org/10.1121/1.4756956

Mottron, L., Bouvet, L., Bonnel, A., Samson, F., Burack, J. A., Dawson, M., Heaton, P. (2013). Veridical mapping in the development of exceptional autistic abilities. Neuroscience and Biobehavioral Reviews, 37, 209-228. https://doi.org/10.1016/j.neubiorev.2012.11.016

Neufeld, J., Roy, M., Zapf, A., Sinke, C., Emrich, H. M., Prox-Vagedes, V., Dillo, W., \& Zedler, M. (2013). Is synesthesia more common in patients with Asperger syndrome?. Frontiers in human neuroscience, 7, 847. https://doi.org/10.3389/fnhum.2013.00847

Niccolai, V., Jennes, J., Stoerig, P., Van Leeuwen, T. M. (2012). Modality and variability of synesthetic experience. American Journal of Psychology, 125, 81-94.

Rakowski, A., Rogowski, P. (2007). Experiments on long-term and short-term memory for pitch in musicians. Archives of Acoustics, 32, 815-826.

Ramachandran, V. S., Hubbard, E. M. (2001). Synaesthesia - A window into perception, thought and language. Journal of Consciousness Studies, 8, 3-34.

Ramachandran, V. S., Hubbard, E. M. (2003). The phenomenology of synaesthesia. Journal of Consciousness Studies, 10, 49-57.

Rich, A. N., Bradshaw, J. L., Mattingley, J. B. (2005). A systematic, large-scale study of synaesthesia: Implications for the role of early experience in lexical-colour associations. Cognition, 98, 53-84.

Rimland, B., Fein, D. A. (1988). Special talents of autistic savants. In Obler, L. K., Fine, D. A. (Eds.), The exceptional brain: Neuropsychology of talent and special abilities (pp. 474492). Guilford Press.

Robertson, L. C., Sagiv, N. (2005). Synesthesia: Perspectives from cognitive neuroscience. Oxford University Press.

Rothen, N., Meier, B. (2010). Higher prevalence of synaesthesia in art students. Perception, 39, 718 720.

Rothen, N., Meier, B., Ward, J. (2012). Enhanced memory ability: Insights from synaesthesia. Neuroscience and Biobehavioral Reviews, 36, 1952-1963.

Schönenberger, I., Burela, V. (2007, January 29). La Synesthésie. https://tecfa.unige.ch/tecfa/teaching/UVLibre/9900/bin19/welcome.htm 
Sergeant, D., Vraka, M. (2014). Pitch perception and absolute pitch in advanced performers. In Papageorgi, I., Welch, G. (Eds.), Advanced musical performance (pp. 201-229). Ashgate.

Siegel, J. A. (1972). The nature of absolute pitch. In Gordon, E. (Ed.), Experimental research in the psychology of music: VIII. Studies in the psychology of music (pp. 65-89). Iowa University Press.

Siegel, J. A. (1974). Sensory and verbal coding strategies in subjects with absolute pitch. Journal of Experimental Psychology, 103, 37-44.

Simner, J. (2012). Defining synaesthesia. British Journal of Psychology, 103, 1-15.

Simner, J., Glover, L., Mowat, A. (2006). Linguistic determinants of word colouring in graphemecolour synaesthesias. Cortex, 42, 281-289.

Simner, J., Mulvenna, C., Sagiv, N., Tsakanikos, E., Witherby, S. A., Fraser, C., Scott, K., \& Ward, J. (2006). Synaesthesia: the prevalence of atypical cross-modal experiences. Perception, 35(8), 1024-1033. https://doi.org/10.1068/p5469

Sitton, S. C., Pierce, E. R. (2004). Synesthesia, creativity and puns. Psychological Reports, 95, $577-$ 580.

Smilek, D., Dixon, M. J., Cudahy, C., Merikle, P. M. (2002). Synesthetic color experiences influence memory. Psychological Science, 13, 548-552.

Takeuchi, A. H., Hulse, S. H. (1991). Absolute-pitch judgments of black-key and white-key pitches. Music Perception, 9, 27-46.

Theusch, E., Basu, A., Gitschier, J. (2009). Genome-wide study of families with absolute pitch reveals linkage to 8q24.21 and locus heterogeneity. American Journal of Human Genetics, $85,112-119$.

Ward, J. (2013). Synesthesia. Annual Review of Psychology, 64, 4975. https://doi.org/10.1146/annurev-psych-113011-143840

Ward, J. (2019). Synaesthesia: A distinct entity that is an emergent feature of adaptive neurocognitive differences. Philosophical Transactions of the Royal Society of London. Series B, Biological Sciences, 374, 20180351. https://doi.org/10.1098/rstb.2018.0351

Ward, J., Huckstep, B., Tsakanikos, E. (2006). Sound-colour synaesthesia: To what extent does it use cross-modal mechanisms common to us all? Cortex, 42, 264-280.

Ward, W. D. (1999). Absolute pitch. In Deutsch, D. (Ed.), The psychology of music (pp. 265298). Academic Press.

Wilson, S. J., Lusher, D., Martin, C. L., Rayner, G., McLachlan, N. (2012). Intersecting factors lead to absolute pitch acquisition that is maintained in a fixed do. Environment. Music Perception, 29, 285-296.

Wilson, S. J., Lusher, D., Wan, C. Y., Dudgeon, P., Reutens, D. C. (2009). The neurocognitive components of pitch processing: Insights from absolute pitch. Cerebral Cortex, 19, 724-732. 


\section{University Library}

\section{- M M I N E R VA A gateway to Melbourne's research publications}

Minerva Access is the Institutional Repository of The University of Melbourne

Author/s:

Glasser, S

Title:

Perceiving Music Through the Lens of Synaesthesia and Absolute Pitch

Date:

2021-07-31

Citation:

Glasser, S. (2021). Perceiving Music Through the Lens of Synaesthesia and Absolute Pitch. PERCEPTION, 50 (8), pp.690-708. https://doi.org/10.1177/03010066211034439.

Persistent Link:

http://hdl.handle.net/11343/281916 